\title{
Electrochemical degradation of diclofenac for pharmaceutical wastewater treatment
}

\author{
Zhaoqi Ji ${ }^{1}$, Tao Liu ${ }^{2}$, Hong Tian ${ }^{3, *}$ \\ ${ }^{1}$ College of Civil Engineering and Architecture, Shandong University of Science and Technology, \\ No.579 Qianwangang Rd, Qingdao Development Zone, Shandong, 266590, China \\ ${ }^{2}$ College of Environmental Science and Engineering, Ocean University of China, No.238 Songling \\ Rd, Laoshan, Qingdao, Shandong, 266100, China \\ ${ }^{3}$ College of Earth Science and Engineering, Shandong University of Science and Technology, No.579 \\ Qianwangang Rd, Qingdao Development Zone, Qingdao, Shandong, 266590, China \\ *E-mail: htiancn@163.com
}

doi: $10.20964 / 2017.08 .72$

Received: 15 March 2017 / Accepted: 13 June 2017 / Published: 12 July 2017

\begin{abstract}
Pharmaceutical compounds are potential bioactive chemicals in the environment, and their removal from water has aroused increasing concern. Novel electrochemical techniques have demonstrated potential application in the treatment of wastewater containing pharmaceuticals. In this study, the degradation of diclofenac in aqueous solution was carried out by an electrooxidation method with boron-doped diamond (BDD) and $\mathrm{Ta} / \mathrm{PbO}_{2}$ anodes. The influence of various operating parameters, such as the applied current density, temperature, initial concentration of diclofenac and $\mathrm{pH}$ value, on the degradation efficiency of diclofenac with the $\mathrm{Ta} / \mathrm{PbO}_{2}$ anode was systematically investigated. In comparison with the BDD anode, the $\mathrm{Ta} / \mathrm{PbO}_{2}$ anode possessed a higher oxidation rate and current efficiency.
\end{abstract}

Keywords: Electrochemical oxidation; Pharmaceutical wastewater; $\mathrm{Ta} / \mathrm{PbO}_{2}$; Removal; BDD

\section{FULL TEXT}

(C) 2017 The Authors. Published by ESG (www.electrochemsci.org). This article is an open access article distributed under the terms and conditions of the Creative Commons Attribution license (http://creativecommons.org/licenses/by/4.0/). 